\title{
A 3D spatiotemporal morphological database for urban green infrastructure and its applications
}

\begin{abstract}
:
The morphology of urban green infrastructure (UGI) will affect the quality of urban environment and the way people perceive. The three-dimensional morphological features of UGI have been proven to be the key factors to effect urban ecological environment, which have rarely been incorporated into the UGI morphology in the previous researches. In this paper, a systematic approach to develop a 3D spatiotemporal morphological database for UGI is proposed. The database is built on a complete set of information describing the form of UGI in the plane, the vertical direction and the temporal changes. In addition, three categories of morphological parameters of UGI are calculated and integrated in the database. User operation and visualization and morphological parameter operation is achievable in the database. The database can be further integrated with simulation programs and analytical models so that it can be used in the design and research of various urban sustainable subjects. In a case study, we further create a complete 3D spatiotemporal morphological database of UGI for an urban district of $4 \mathrm{~km}^{2}$ in Nanjing, China.

\section{Keywords:}

Urban green infrastructure; Urban morphological database; 3D modeling; Spatiotemporal; Morphological analysis; GIS

\section{Introduction}

Due to the progression of global urbanization, $55 \%$ of the world's population is living in cities, and this is expected to reach $68 \%$ by 2050 (UN, 2018). Although cities offer many 
benefits and opportunities to people, they are facing serious environmental problems such as the urban heat island effect, increased energy consumption, floods, air pollution, and reduced biodiversity (Whitford, Ennos, \& Handley,2001; Wilby \& Perry, 2006; McMichael, 2000). Urban green infrastructure (UGI) is an indispensable component of a city and a key functional system to modulate the urban environment and provide urban dwellers with livable and even enjoyable spaces. Different UGI terms can be found in the literature, with common ones being green spaces, green elements, green environments, greenery, green areas, green sites, and green systems (Taylor \& Hochuli, 2017). The definition of UGI varies slightly among different disciplines (Bilgili \& Gökyer, 2012). For the purpose of this study, UGI is defined as the ecological area transformed from the natural ecosystem to an urban space or artificially constructed by human beings, and it is mainly composed of vegetation and waters (Lo \& Jim, 2012; Bilgili et al., 2012; Aydin \& Çukur, 2012; Dunnett, Swanwick, \& Woolley, 2002). With integration of natural and constructed regions, the "urbanization" green space categories emerge. Apart from the residual patches of the original ecosystem such as forests and riparian zones, landscapes created and managed by human beings such as parks, street landscapes and gardens widely exist in urban areas (Abd Aziz \& Rasidi,2013). With the aggravation of land use, landscape heterogeneity and fragmentation increase. Urban green structure (spatial composition and configuration of UGI) is usually used to describe the UGI form in an urban area, focusing on characteristics of connectivity and multi-function (Madureira, Andresen, \& Monteiro,2011).

UGI exists and blends into urban open spaces, bringing environmental, economic and social benefits to residents and society (Roy, Byrne, \& Pickering,2012). The extensive environmental benefits provided by UGI include storing carbon and eliminating air pollutants (Nowak, Crane, \& Stevens,2006; Tallis, Taylor, Sinnett, \& Freer-Smith,2011), reducing noise pollution (Pathak, 
Tripathi, \& Mishra,2011), stormwater management (Berland et al.,2017), regulating the temperature of the environment (Nowak et al.,2006; Cummins \& Jackson, 2001), decreased energy consumption (McPherson, 1994), reducing wind speed in residential areas (Heisler,1990) and preserving biological diversity (Godefroid, 2001). UGI brings economic benefits such as producing food (Clark \& Nicholas, 2013), increasing the value of land and housing (Gao \& Asami,2007; Noh,2019), and promoting tourism to bring local benefits (Majumdar, Deng, Zhang, \& Pierskalla,2011). Social benefits created by UGI include enhancing the attractiveness of cities' living, working, investment and tourism (Baycan-Levent, Vreeker, \& Nijkamp,2009), providing citizens with opportunities for entertainment, aesthetic and social intercourse (Zhou \& Parves, 2012), and improving citizens' physical and mental health (Hansmann, Hug, \&

Seeland,2007). Fig. 1 illustrates the effect of UGI on the urban physical environment.

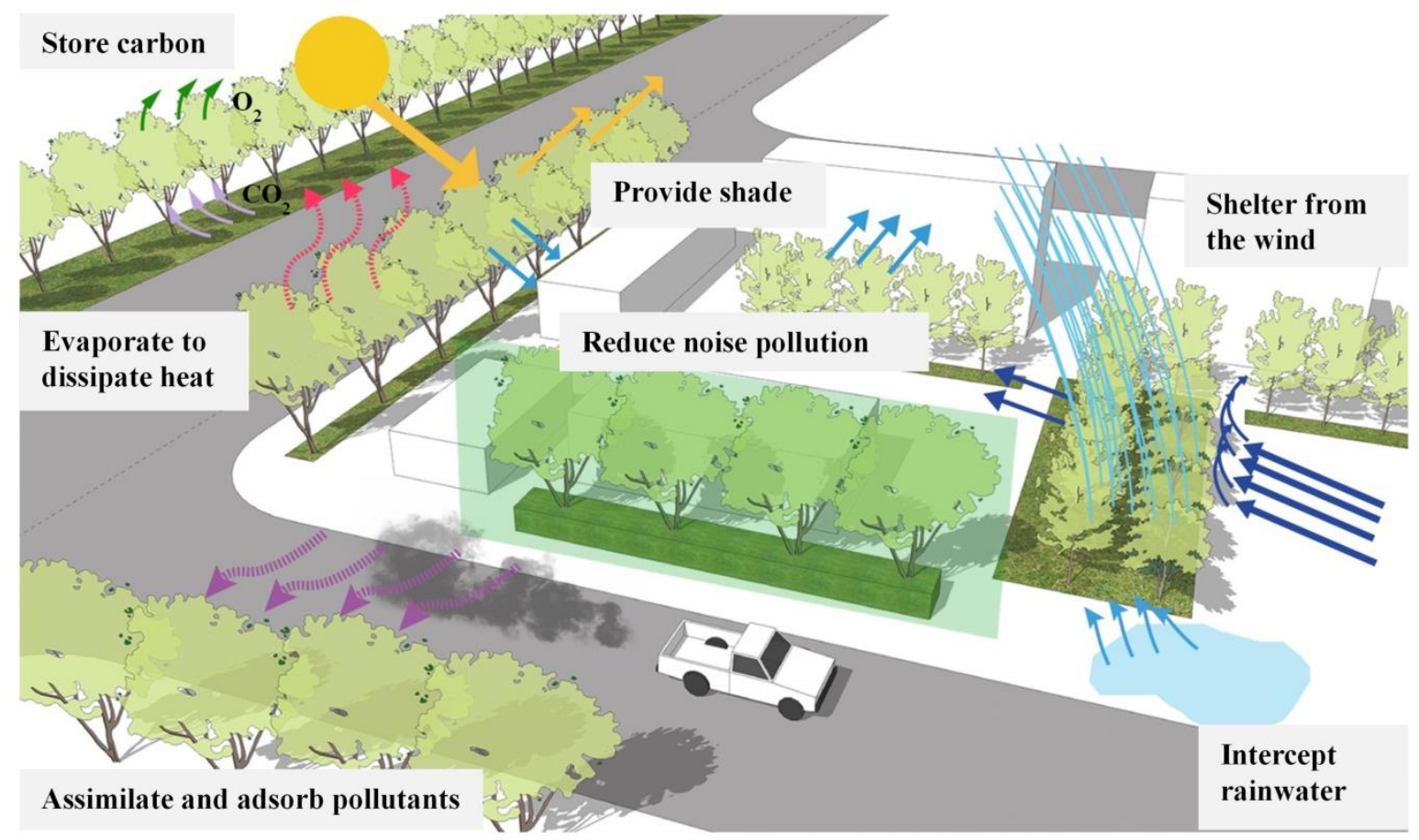

Fig. 1. The effect of UGI on the urban physical environment including shading, pollutant diffusion, rainwater interception, evaporation, wind sheltering, etc. 
The function of UGI in a city depends on many factors, among which its morphology is critical. According to the definition of the urban morphology (Schirmer \& Axhausen, 2016), the UGI morphology can be defined as the science that studies the physical geometry, internal constitution, process and factors that control and influence the geometry of UGI. In the research works investigating UGI morphology, the methodology of spatial analysis in landscape ecology is widely adopted. The morphological concept in landscape ecology originates from the study of the landscape pattern using the "patch-corridor-matrix" as the basic model (Forman \& Godron, 1986; Forman, 1995). The quantitative indexes of the spatial pattern, mainly used to depict the composition and structural heterogeneity of the landscape, reflect the landscape mosaic caused by disturbances (O'Neill et al., 1988; Turner, 2005; Gustafson, 1998). The graph theory in landscape ecology is a useful tool for studying the landscape connectivity and ecological network on the macro scale (Uy \& Nakagoshi, 2007; Rudd, Vala, \& Schaefer, 2002; Lu,2015). As characteristics related to human activities, the accessibility and justice of UGI are also hot spots of research (Wolch, Byrne, \& Newell, 2014; La Rosa, 2014). The planning method of UGI as an element of creation and transformation of sustainable communities subsequently developed. Landscape ecological principals are applying to planning if UGI in compact cities to optimizes its connectivity (Jim and Chen, 2003; Madureira, Andresen, \& Monteiro,2011). Greenway is the most important form of urban green structure with characteristics of multifunction and linear connection to realizes the connection between fragmented cities and natural areas (Little, 1990; Bryant, 2006; Walmsley, 1995). Greenway has been incorporated into the main planning methods of landscape planning and widely practiced and confirmed in the United States, Europe, Singapore and other regions. (Ahern,1995; Kowarik,2019; Tan,2006; Jongman, Külvik, \& Kristiansen,2004). UGI and urban open space planning are integrated to give full play 
to UGI's social service function, especially in the compact urban form (Byrne \& Sipe,2010; Haaland \& van den Bosch,2015; Maruani \& Amit-Cohen,2007).

The research works mentioned above contribute in different ways to the understanding of UGI morphology and its effect on the urban environment and other urban sustainability issues. However, most of these works focus on the two-dimensional (2D) form and pattern of UGI, neglecting or inadequately addressing its three-dimensional (3D) features. The key characteristics of the 3D form of UGI include the height of plants, the canopy volume, the leaf area index ( $L A I)$, etc. The 3D features of UGI have a profound impact on its ecological functions. Li et al confirmed that the $L A I$ and branch character are relevant to the interception efficiency of rainwater by plants ( $\mathrm{Li}$ et al., 2016). The $L A I$, porosity and height-to-width ratio of plants have been proven to be factors affecting the air velocity around plants (Manickathan, Defraeye, Allegrini, Derome, \& Carmeliet, 2018; Russell et al., 2018; Cheng et al., 2018). A number of empirical studies (Manickathan et al., 2018; Rahman et al., 2020; Wang et al.,2020) confirmed that the $L A I$ and canopy size are positively correlated with both cooling mechanisms of vegetation (evaporation and shadow). In addition, the features of leaves including their size, thickness and stomatal resistance have certain effects on cooling (Ballinas \& Barradas, 2016; Manickathan et al., 2018; Rahman et al., 2020). Tong et al evaluated the influence of the leaf area density $(L A D)$ on the diffusion of traffic pollutants (Tong, Baldauf, Isakov, Deshmukh, \& Max Zhang, 2016; Wang, Li, \& Wang, 2018). Hsieh et al demonstrated the influence of the height, crown density and species of trees on reducing the energy use of buildings (Hsieh, $\mathrm{Li}$, Zhang, \& Schwegler, 2018). Although the 3D features of UGI have been proven to be key factors to the environment, the above studies are limited to single plants or clumps of trees with few macroscopic morphological analyses being conducted. 
In addition to its 3D morphology, the temporal change of UGI should not be overlooked. Deciduous trees, both along streets or in parks, are an essential component of UGI and account for a significant portion of the total amount of greenery. A deciduous tree full of leaves in the summer differs greatly from one without leaves in the winter in terms of providing shading and cooling (Chen et al., 2019), blocking or resisting wind (Manickathan et al., 2018), absorbing solar radiation, consuming carbon dioxide, generating oxygen, etc. The dynamic change of leaves controls the physical and biochemical processes of the urban canopy and greatly affects the exchange of energy and mass between the earth's surface and the atmosphere (Xin et al., 2018). Therefore, the temporal change of UGI should be considered when its morphology and impact on the urban environment are studied.

In addition to the morphology of UGI itself, the relationship between UGI and its surrounding urban elements such as buildings should not be overlooked. Green space and other land use in cities tend to be highly mixed (Belmeziti, Cherqui, \& Kaufmann, 2018; Burton, Jenks, \& Williams, 2003), where vegetation and other elements interact (Pickett \& Cadenasso, 2008). The form of the architecture, urban canyon and UGI work together to affect the urban microclimate (Perini \& Magliocco, 2014, Ballinas et al., 2016), the diffusion of pollutants (Wang, Li, \& Wang, 2018) and the energy consumption of buildings (Hsieh et al., 2018). The morphological correlation between UGI and its adjacent urban elements is critical for understanding their ecological effects and benefits. However, such studies are insufficient. They either exclusively focus on the UGI or mainly investigate non-UGI urban elements.

In summary, the morphology of UGI plays an important role in creating and affecting the urban environment and other urban sustainable issues. Although numerous research works have been conducted from different angles to gain an understanding of the UGI morphology and its 
sustainable functions, some research gaps, as discussed previously, can still be identified. This paper presents a systematic methodology to develop a morphological database of UGI. The database includes both 2D and 3D features of UGI. The temporal change of UGI, mainly as it relates to deciduous trees, is considered in the database. Besides, the relationship between the morphology of UGI and that of its adjacent urban spaces is addressed.

The remainder of this paper is organized as follows. Section 2 explains the methodology of the study, including the case study area in section 2.1, the framework of the 3D spatiotemporal database of UGI in section 2.2, the definitions of the morphological parameters of UGI in section 2.3, and the data acquisition and quality control in section 2.4. Section 3 presents the main results, including the user operations and visualization of the database in section 3.1 , the basic morphological parameters in section 3.2, and the advanced morphological parameters in section 3.3. Further discussions are made in section 4. Section 5 concludes the paper and offers an outlook on future research.

\section{Methodology}

\subsection{Case study area}

Although the general methodology to develop the 3D spatiotemporal morphological database for UGI is universal, the determination of the specific parameters depends on the area studied. Therefore, we selected an urban district in Nanjing, China, as the case study area to demonstrate the proposed methodology. Nanjing is a major city with approximately 8 million people in the Yangtze River Delta Region of China. Nanjing has a subtropical humid climate with four distinct seasons and abundant rainfall. Fig. 2 illustrates the location of Nanjing and the urban district selected for study. The urban district covers 85 city blocks defined by streets and is 
approximately $4.02 \mathrm{~km}^{2}$ in area. The study area is located near the epicenter of the city and thus exhibits a typical high-density urban form dominated by many high-rise office, commercial, and residential buildings.

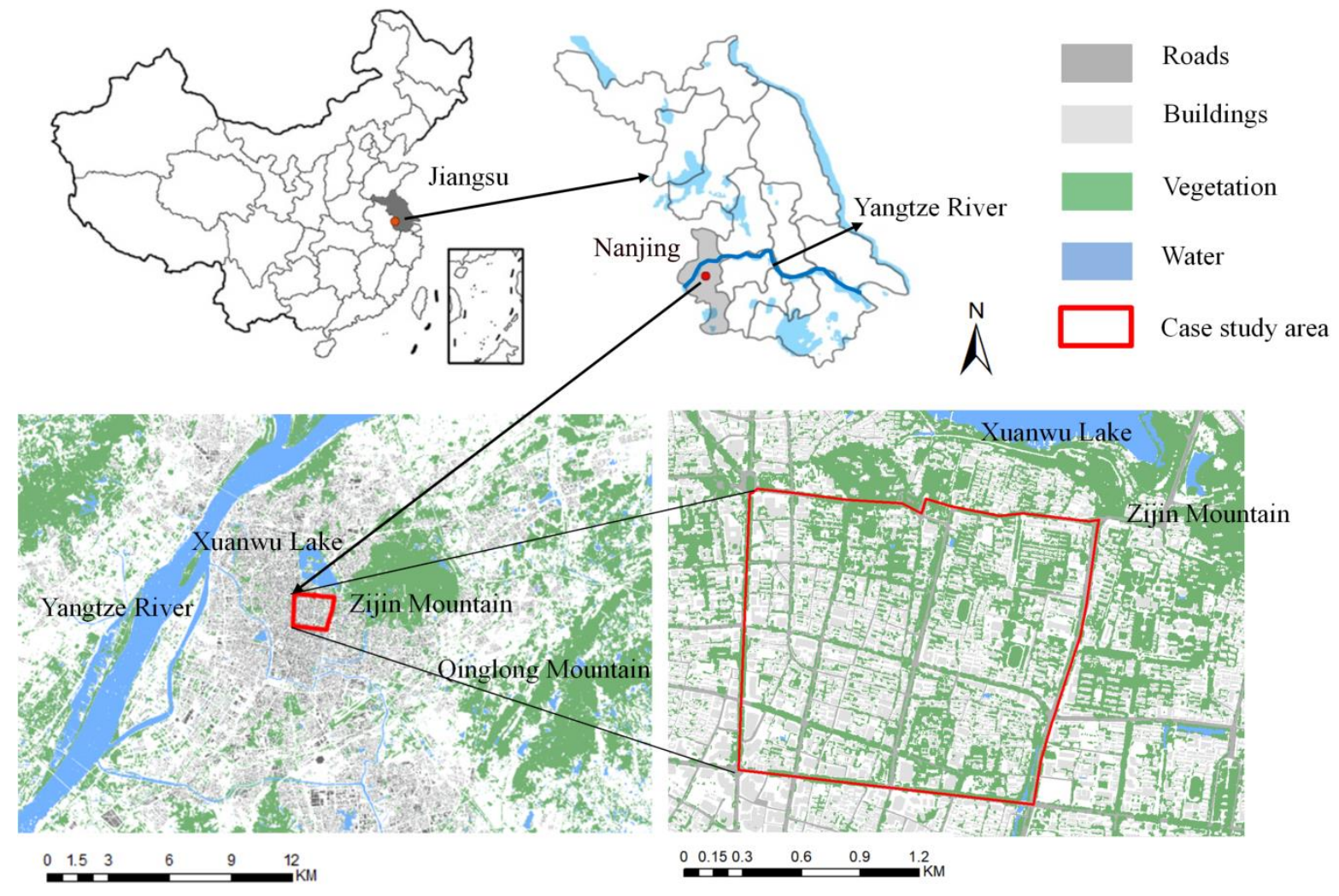

Fig. 2. The location of Nanjing and the selected urban district for this study.

\subsection{Framework of the 3D spatiotemporal morphological database of UGI}

Fig. 3 illustrates the overall structure of the 3D spatiotemporal morphological database of UGI. The database consists of 4 main functional components, namely, data collection and input, the 3D spatiotemporal morphology of UGI, the 3D urban form, and analysis and application. 


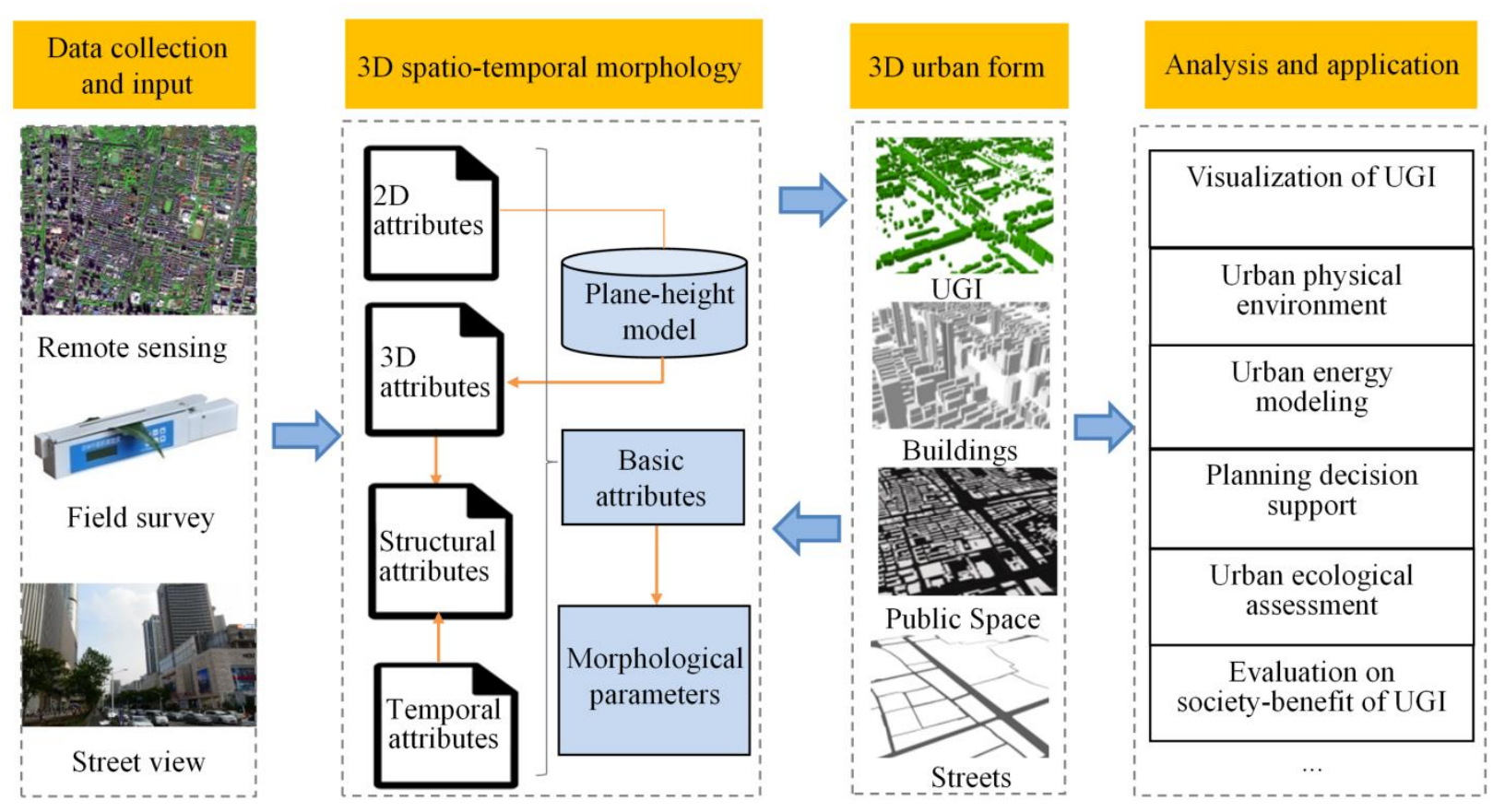

Fig. 3. Framework of the 3D spatiotemporal morphological database of UGI.

Data collection and input is the first component of the database, serving the function of collecting and inputting the basic data needed to build the database. The primary data sources include remote sensing, field surveys, and street views. Using the collected data and the models presented later, the 3D spatiotemporal morphology of UGI is created, which consists of plane attributes, plane-height relationships, height attributes, structural attributes, temporal characteristics, and morphological parameters. Since the morphology of UGI is embedded in and interwoven with the urban form, the 3D urban form component provides the database with the necessary information to generate a complete model with UGI, buildings, public spaces, and streets. With the 3D spatiotemporal morphology of UGI and the 3D urban form established, a variety of analyses can be conducted for different applications. These include but are not limited to the visualization of UGI, an urban physical environment simulation, urban energy modeling, urban ecological assessment, and a societal benefit evaluation. 


\subsection{Morphological attributes and parameters}

In Fig. 3, Patches of UGI with the same morphological attributes are defined as the basic unit of UGI. Unlike the morphological attributes, morphological parameters describe the morphology of UGI in a certain urban area encompassing multiple and sometimes many UGI patches. The morphological parameters can be categorized into three groups, namely, 2D morphological parameters, 3D morphological parameters, and correlative parameters. The 2D and 3D morphological parameters describe and quantify the morphology of UGI itself. The correlative parameters are intended to reflect the correlation between UGI and the urban form that it is mixed with or embedded in.

\subsubsection{Morphological attributes of basic UGI units}

Morphological attributes include (a) the 2D morphological attributes such as the projection profile of the crown, the crown diameter, and the tree species, (b) the 3D morphological attributes such as the crown height, the total tree height, the height to the crown base, and the crown shape, and (c) the canopy structure morphological attributes. The canopy structure morphological attributes reflect the composition and the internal structure of the tree canopy, including the canopy volume index $(C V I), L A D$ and $L A I$. $C V I$ is defined as the canopy volume per unit area of the projection profile of the crown, usually expressed in $\mathrm{m}^{3} / \mathrm{m}^{2}$. LAI is the total leaf area per unit area of the projected profile of the crown. $L A D$ is defined as the total leaf area of vegetation per unit of the crown volume, usually using $\mathrm{m}^{2} / \mathrm{m}^{3}$ as unit. The conversion formula among the three is as follows:

$$
L A I=L A D * C V I
$$


The database as presented in Fig. 3 contains the basic spatial and temporal information of UGI. Based on this information, a variety of UGI morphological parameters can be calculated and stored in the database. These parameters are a key component of the database and of great value when the database is applied to analyzing, evaluating, and designing sustainable UGI and cities.

\subsubsection{D/3D morphological parameters of UGI}

The 2D morphological parameters describe and quantify the morphology of UGI in the horizontal plane. They are the most fundamental morphological parameters and widely used in landscape ecology, urban studies, urban planning and design, and other relevant disciplines. Table 1 contains the 2D morphological parameters that are considered and integrated in the database including Total Area, Total edge, Landscape Shape index, Area-Weighted Mean Shape Index and Mean Patch Size. In addition to the definition and calculation formula, their time-dependent nature, being dynamic or static, is given. The 2D morphological parameters can be further extended to the 3D level by considering the features of UGI in the vertical direction. Table 1 contains the 3D morphological parameters considered and integrated in the database, including total volume, total leaf area, volume -weighted mean shape index, leaf area-weighted mean shape index, mean patch volume, mean height, mean crown height, and mean leaf area index. 


\section{Table 1}

Definition, formulas, and time-dependent nature of the 2D/3D morphological parameters and correlative parameters defining the magnitude and intensity of UGI in an urban space.

\begin{tabular}{|c|c|c|c|c|}
\hline Index & Definition & Formula & Static/ Dynamic & Dimension \\
\hline Total Area $(T A)$ & Total projected area of the UGI crown & $S_{j}$ & Static & $2 \mathrm{D}$ \\
\hline Total Edge $(T E)$ & Total perimeter length of the crown projection profile & $E_{j}$ & Static & $2 \mathrm{D}$ \\
\hline Landscape Shape index $(L S I)$ & $\begin{array}{l}\text { Index to measure the planar complexity of the landscape } \\
\text { by calculating the degree of the deviation between the } \\
\text { shape and a square or a circle }\end{array}$ & $\frac{0.25 T E}{\sqrt{T A}}$ Or $\frac{T E}{2 \sqrt{\pi T A}}$ & Static & 2D \\
\hline $\begin{array}{l}\text { Area-Weighted Mean Shape } \\
\text { Index }(A W M S I)\end{array}$ & $\begin{array}{l}\text { The mean LSI taking the proportion of each patch area to } \\
\text { the total area as the weight coefficient }\end{array}$ & $\sum_{j}^{m} L S I_{j} * \frac{S_{j}}{T A}$ & Static & 2D \\
\hline Mean Patch Size (MPS) & The total area of UGI divided by the number of patches & $\frac{T A}{m}$ & Static & 2D \\
\hline Total Volume (TV) & Total volume of the crown in the statistical area & $\sum_{i} C V I_{i} S_{i}$ & Static & $3 \mathrm{D}$ \\
\hline Total Leaf Area (TLA) & Total leaf area of the crown in the statistical area & $\sum_{i}^{n} L A I_{i} S_{i}$ & Dynamic & $3 \mathrm{D}$ \\
\hline $\begin{array}{l}\text { Volume -Weighted Mean } \\
\text { Shape Index (VWMSI) }\end{array}$ & $\begin{array}{l}\text { The mean Landscape Shape Index calculated with the } \\
\text { proportion of each patch volume to the total volume as the } \\
\text { weight coefficient }\end{array}$ & $\sum_{j}^{m} L S I_{j} * \frac{V_{j}}{T V}$ & Static & $3 \mathrm{D}$ \\
\hline
\end{tabular}


Leaf Area-Weighted Mean

Shape Index (LAWMSI)

Mean Patch Volume (MPV)

Mean Patch Leaf Area (MPLA)

Mean Height $(M H)$

Mean Crown Height $(\mathrm{MCH})$

Mean Leaf Area Index (MLAI)

Greening Rate $(G R)$

Volume Rate $(V R)$

Leaf Area Rate (LAR)

Volume-Weighted GreeningBuilding Ratio (VWGBR)

Leaf Area-Weighted GreeningBuilding Ratio ( $L A W G B R$ )

Greening-Building Height Ratio (GBHR)
The mean Landscape Shape Index calculated with the proportion of leaf area in each patch to the total leaf area as the weight coefficient

The total volume of UGI divided by the number of patches

The total leaf area of UGI divided by the number of patches

Average tree height in the crown projection area

Average crown height in the crown projection area

Average $L A I$ in the crown projection area

Ratio of crown projection area to land area

Average crown volume per unit of land area

Average leaf area per unit of land area

Ratio of the canopy volume to the building volume

Ratio of the leaf area to the building volume

Ratio of the average height of the UGI to that of the buildings

$$
\sum_{j}^{m} L S I_{j} * \frac{L A_{j}}{T L A} \quad \text { Dynamic }
$$

$\begin{array}{lcc}\frac{T V}{m} & \text { Static } & \text { 3D } \\ \frac{T L A}{m} & \text { Dynamic } & 3 \mathrm{D} \\ \frac{\sum_{i}^{n} H_{i} S_{i}}{T A} & \text { Static } & \\ \frac{T V}{T A} & \text { Static } & 3 \mathrm{D} \\ \frac{T L A}{T A} & \text { Dynamic } & 3 \mathrm{D} \\ \frac{T A}{S_{L}} & \text { Static } & \text { 2D } \\ \frac{T V}{S_{L}} & & 3 \mathrm{D} \\ \frac{T L A}{S_{L}} & \text { Static } & 3 \mathrm{D} \\ \frac{T V}{V_{B}} & & 3 \mathrm{D} \\ \frac{T L A}{V_{B}} & \text { Dynamic } & \\ \frac{M H}{H_{B}} & & 3 \mathrm{D}\end{array}$

$E_{j}$ is the perimeter length of the $j$ th UGI patch; $S_{j}$ is the area of the $j$ th UGI patch; $L S I_{j}$ is the Landscape Shape Index of the jth patch; $V_{j}$ is the crown volume of the jth patch; $\mathrm{LA}_{\mathrm{j}}$ is the leaf area of the $j$ th patch; $\mathrm{m}$ is the total number of patches; $\mathrm{CVI}_{\mathrm{i}}$ is the crown volume index of the $i$ th basic $\mathrm{UGI}$ unit; $\mathrm{LAI}_{\mathrm{i}}$ is the leaf area index of the $i$ th basic UGI unit; Hi is the tree height of the $i$ th basic UGI unit; Si is the projection area of the $i$ th basic UGI unit; $n$ is 
the total number of basic UGI units; $\mathrm{S}_{\mathrm{L}}$ is the land area of the statistical urban space; $\mathrm{V}_{\mathrm{B}}$ is the total volume of the buildings; and $\mathrm{H}_{\mathrm{B}}$ is the mean height of the buildings.. 


\subsubsection{Correlative parameters}

The correlative parameters of UGI quantify the relationship between UGI and its adjacent urban spaces and elements. The correlative parameters can be divided into two categories, namely, the parameters defining the magnitude and intensity of UGI in an urban space and the parameters reflecting the spatial relationship between UGI and its adjacent urban form. Table 1 lists the correlative parameters defining the magnitude and intensity of UGI in an urban space including greening rate, volume rate, leaf area rate, volume-weighted greening-building ratio, leaf area-weighted greening-building ratio, and greening-building height ratio.

Five correlative parameters are proposed to reflect the spatial relationship between UGI and its adjacent urban form, namely, the mixed variance, aggregation index, dispersion index, eccentricity index, and centripetal index, representing the distribution changes of UGI in the statistical area in three aspects (Fig. 4). The calculation of these parameters adopts the grid spatial overlay analysis method. In this research, a $10 \mathrm{~m} * 10 \mathrm{~m}$ grid is used.

\section{mixed variance}

The mixed variance of UGI is used to characterize the degree of integration of UGI and the urban background, reflecting the centralized or uniform characteristics of UGI distribution. Fig. 4 (a) shows the graphical characteristics of UGI and background from a poorly mixed state to a highly mixed state. 
(a)

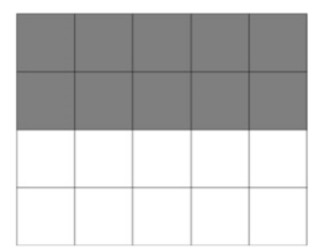

Highly separated state

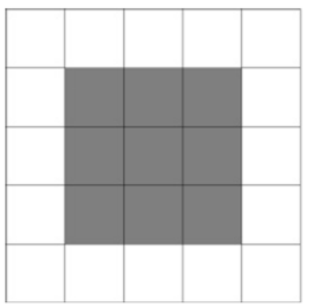

Highly aggregated state

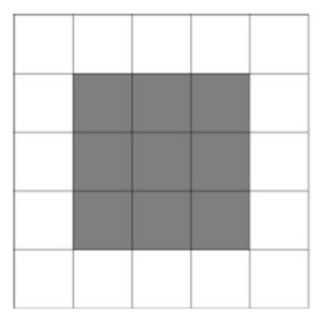

Highly centripetal state

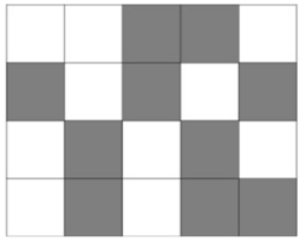

Partially mixed state

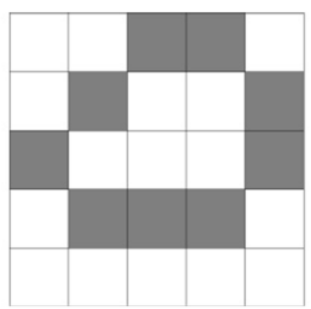

Partially discrete state

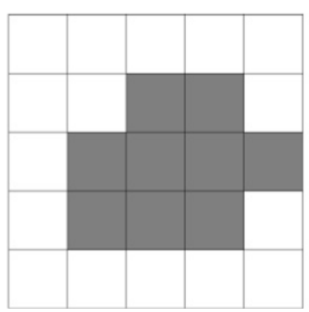

Partially eccentric state

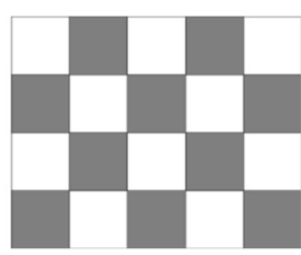

Highly mixed state

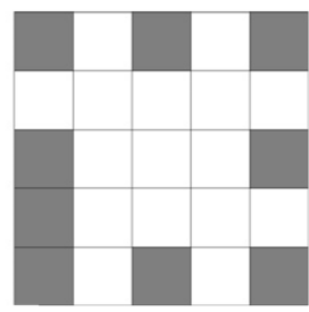

Highly discrete state

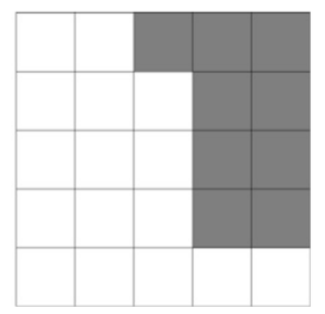

Highly eccentric state

Fig. 4. The graphical characteristics of the state of the distribution of UGI relative to the background in three aspects, including the following: (a) the degree of mixing, (b) the degree of aggregation, and (c) the degree of eccentricity.

The mixed variance $(M V)$ is calculated as follows:

$$
M V=\frac{1}{n} \sum_{i=1}^{n}\left(a_{i}-\bar{a}\right)^{2}
$$

where $n$ is the total number of grids, $a_{i}$ is the ratio of UGI projected area/crown volume/leaf area in the $i$ th grid to the area of a single grid, and $\bar{a}$ is the ratio of the total UGI projected area/crown volume/leaf area to land area. The higher the mixed variance is, the more uneven the UGI distribution. 


\section{aggregation index and dispersion index}

The aggregation index $(A I)$ is a measure of the degree to which UGI tends to be concentrated at a point in a region. In contrast, the dispersion index $(D I)$ demonstrates the degree of dispersion of the UGI's position from its geometric center point. Fig. 4 (b) shows the graphical features of UGI from a highly aggregated to a highly discrete distribution. To obtain the 2D and 3D UGI morphological characteristic indexes, respectively, we first define the weight coefficient $\mathrm{k}_{\mathrm{i}}$ as in Table 2.

\section{Table 2}

Formula of the weight coefficient $k_{i}$.

\begin{tabular}{ccc}
\hline Reference Attributes & Calculation formula & Dimension \\
\hline Crown Projection Area & $k_{i}=\frac{S_{i}}{S_{t}}$ & $2 \mathrm{D}$ \\
Crown Volume & $k_{i}=\frac{V_{i}}{V_{t}}$ & $3 \mathrm{D}$ \\
Leaf Area & $k_{i}=\frac{L A_{i}}{L A_{t}}$ & $3 \mathrm{D}$
\end{tabular}

$\mathrm{S}_{\mathrm{i}}$ is the area of UGI in the $i$ th grid; $S_{t}$ is the total area of UGI in the statistical area; $V_{i}$ is the crown volume in the ith grid; $V_{t}$ is the total canopy volume; $L A_{i}$ is the leaf area in the $i$ th grid; and $L A_{\mathrm{t}}$ is the total leaf area.

The standard distances of UGI and land were calculated separately, and they are represented by $S D_{G}$ and $S D_{L}$, respectively:

$$
S D=\sqrt{\frac{\sum_{i=1}^{n} k_{i}\left(x_{i}-\bar{x}\right)^{2}}{\sum_{i=1}^{n} k_{i}}+\frac{\sum_{i=1}^{n} k_{i}\left(y_{i}-\bar{y}\right)^{2}}{\sum_{i=1}^{n} k_{i}}}
$$

where the coordinates of the ith grid center point are $\left(x_{i}, y_{i}\right)$. The geometric center coordinates of UGI or land are $(\bar{x}, \bar{y}), n$ is the total number of grids.

$D I$ is defined as (4) and $A I$ is defined as (5): 


$$
\begin{gathered}
D I=\frac{S D_{G}}{S D_{L}} \\
A I=2-D I
\end{gathered}
$$

The higher $A I$ is, the more concentrated the UGI; the closer $A I$ is to 1 , the more uniform the UGI. When $A I$ is less than 1 , UGI tends to be discrete and edge distributed. eccentricity index and centripetal index

As shown in Fig. 4 (c), the degree to which the geometric center point of UGI deviates from the center point of the statistical area is called the eccentricity of UGI. The formula of the eccentricity index $(E I)$ is as follows:

$$
E I=\frac{\Delta D}{S D_{L}}
$$

where $S D_{L}$ is the standard distance of the statistical area and $\Delta D$ is the distance from the geometric center of UGI to the geometric center of the land. $\Delta D$ is calculated as follows:

$$
\Delta D=\sqrt{(\bar{x}-\bar{X})^{2}+(\bar{y}-\bar{Y})^{2}}
$$

where the geometric center coordinates of UGI are $(\bar{X}, \bar{Y})$ and the geometric center coordinates of the statistical area are $(\bar{x}, \bar{y})$.

The centripetal index $(C I)$ is defended as the reverse index of $E I$ :

$$
C I=2-E I
$$

\subsection{Data acquisition and quality control}

To calculate the morphological parameters, five basic UGI properties need to be known, namely, the tree species, canopy projection, height, crown volume and $L A D$. 
The tree species and canopy projection were determined by combining multiple data sources including Google Earth, Baidu street view, and field surveys. The canopy projection was acquired using the remote sensing images from Google Earth. The identification of tree species was made by distinguishing their colors in different seasons using Google Earth map and Baidu street view. When the confidence level was low, a field survey was conducted. More than 40 tree species were identified in the urban district. The 26 most common, i.e., dominant, tree species in Nanjing were selected to represent all trees. Other nondominant trees were replaced by the dominant ones with similar crown shapes and growth patterns. The selected dominant tree species account for $96 \%$ of UGI in terms of the area and $97 \%$ in terms of the volume.

Using the "crown diameter - crown height" equation and average crown ratio, the height of UGI is acquired. The "crown diameter - crown height" equations of common tree species in of eastern Chinese cities with subtropical monsoon climate from previous case studies (Liang et al., 2017, Zhou \& Sun, 1995, Guo, 2009) is used for predicting the crown height. The general form of the logistic curve equation to describe the growth factors of plants is:

$$
y=\frac{1}{a+b e^{-c x}}
$$

where $x$ is the crown diameter, $y$ is the crown height, $b$ is the regression coefficient, and $a$ and $c$ are the coefficients. The crown height of a shrub in this research is directly defined as $0.3 \mathrm{~m}$. The average crown ratio is used to calculate the tree height. The crown ratio is defined as the crown length divided by the total tree height, which is mainly determined by the tree species, and is affected by environmental factors such as slope and aspect (Hasenauer \& Monserud, 1996). We measured samples of the dominant tree species in Nanjing and calculated the average crown ratio of each dominant tree species (Fig. 5). For a shrub, the crown ratio is defended as 1. 


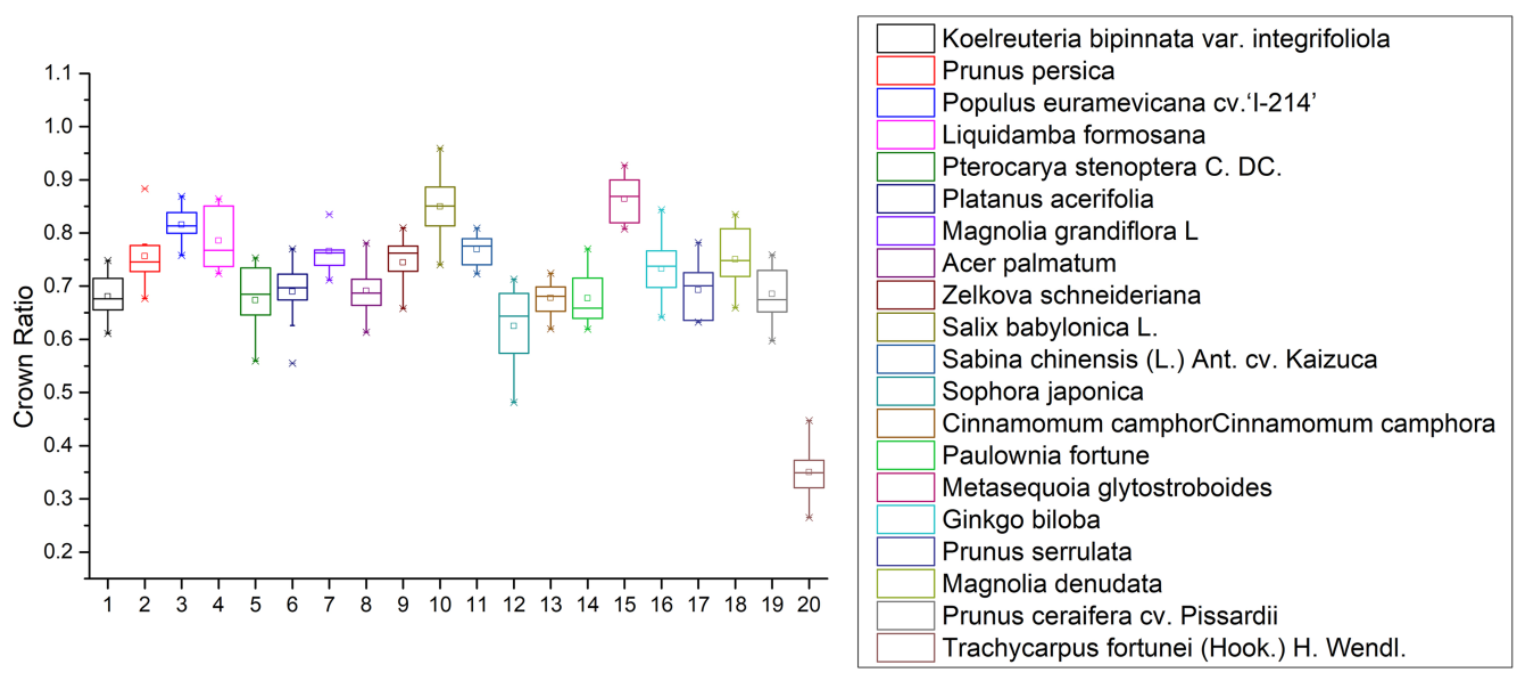

Fig. 5. Distribution of the crown ratios of the dominant tree species in Nanjing.

\section{Table 3}

Six types of tree shapes and their volume formulas.

\begin{tabular}{cc}
\hline Crown Type & Crown Volume Formula \\
\hline Sphere & $\frac{\pi x^{2} y}{6}$ \\
Cone & $\frac{\pi x^{2} y}{12}$ \\
Oval & $\frac{\pi x^{2} y}{6}$ \\
Cylinder & $\frac{\pi x^{2} y}{4}$ \\
Spherical Segment & $\frac{\pi\left(2 y^{3}-y^{2} \sqrt{4 y^{2}-x^{2}}\right)}{3}$ \\
Spherical Sector & $\frac{x\left(3 x y^{2}-2 y^{3}\right)}{6}$
\end{tabular}

In the crown volume formula, $x$ is the crown diameter, and $y$ is the crown height.

The crown volume of trees can be determined by combing the crown diameter, crown

height, and tree species. The crowns can be categorized into 6 types (Zhou \& Sun, 1995), as

summarized in Table 3. The dynamic LAD of UGI comes from the practical measurement values

of different urban dominant species every month. According to the vegetation division of China, 
Nanjing is located in a mid-latitude subtropical area. Its natural vegetation is dominated by deciduous broad-leaved species. Deciduous trees accounted for $70.87 \%$ of UGI coverage in the study area, meaning that the $L A D$ in the area changes greatly in a year. In this study, the $L A D$ of the local dominant tree species in Nanjing in every month measured by Guo (2009) is used.

\section{Results}

\subsection{User operation and visualization}

The 3D spatiotemporal morphological database of UGI for the case study area was developed in ArcGIS (10.5 Esri). The database is composed of 3 levels of data, information, and parameters, namely, basic UGI unit level, the block level, and the district level. Users can access the database at any of these three levels and in the areas that they choose. The basic user operations include visualization, data query and retrieval, morphological operation, view analysis, and data output. Fig. 6 illustrates several basic user operations of the database.

- Visualization. Using ArcScene built in ArcGIS, one can visualize the 3D model of UGI and the surrounding urban elements. The visualization user interface of the database offers functions such as scene roaming and navigation, layer control of the urban elements, map plotting, distance and height measurement, and layer symbolic rendering.

- Data Query and Retrieval. The morphological attributes of the basic UGI unit and the morphological parameters of UGI in the selected plots/blocks/districts can be queried and retrieved. In addition, the surrounding search, attribute retrieval and location of UGI data are supported.

- Morphological Calculation and View Analysis. The morphological calculation process is integrated into a toolkit through the Model Builder, which can process the calculations in 
batches and achieve high efficiency. The view analysis takes the 3D model of UGI into consideration, including the functions of intervisibility analysis and horizon analysis.

- Data Output. The database supports the output of the 3D digital model, UGI 3D view, the parameters of UGI in a specified area in spreadsheet or other formats, symbolic rendered images, etc.

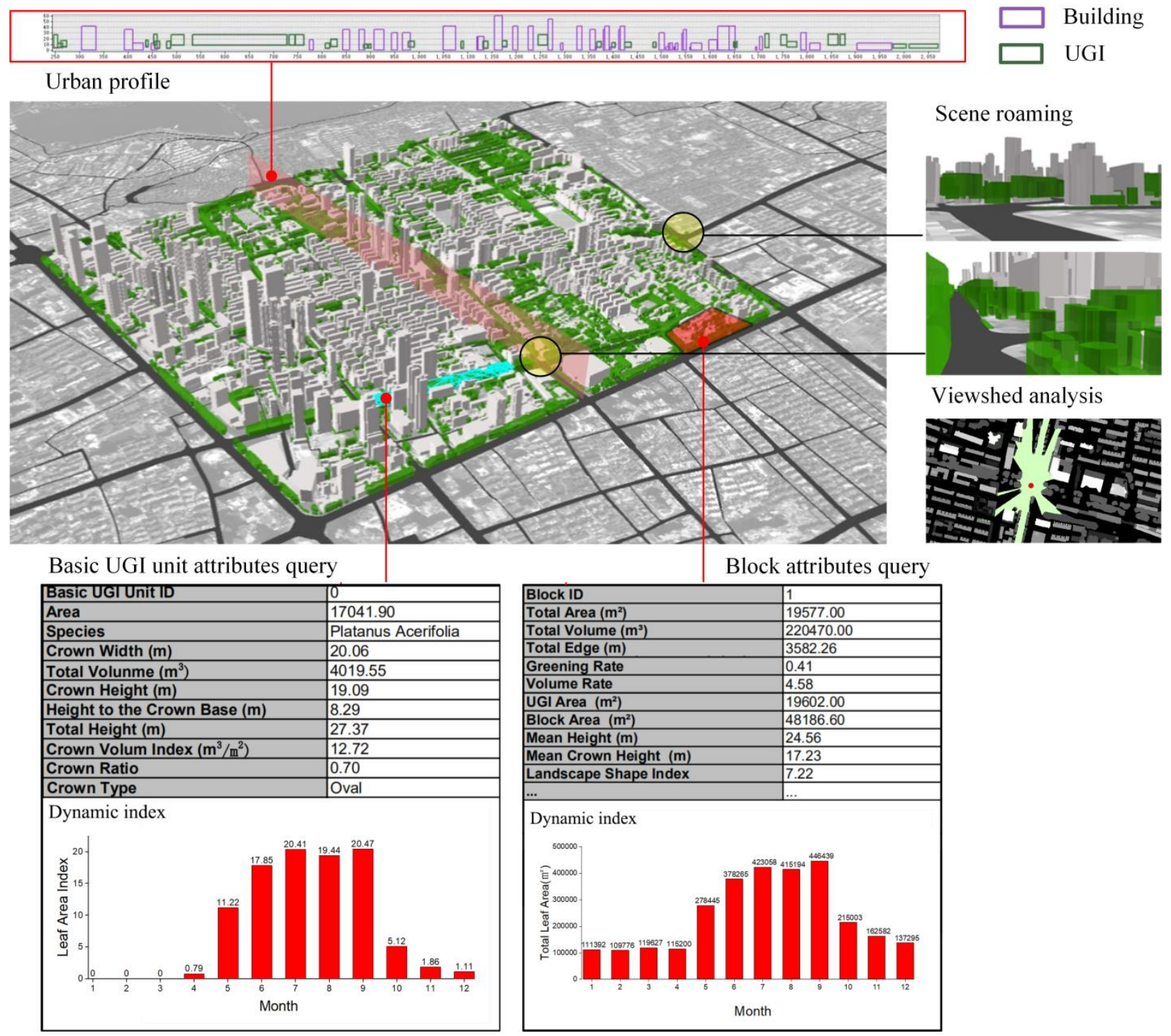

Fig. 6. User operation and visualization of the 3D spatiotemporal morphological database of UGI. 


\subsection{Morphological attributes and parameters of UGI}

\subsubsection{Morphological attributes of the basic UGI units}

The basic morphological attributes of UGI include the crown diameter, crown height, total height, crown ratio and crown volume index. These attributes vary with space but not with time. Fig. 7(a)-(b) illustrates the distribution of two basic attributes in the case area. Note that the attributes are linked to each basic UGI units.

\subsubsection{D/3D morphological parameters of UGI in the case study area}

The database contains a variety of 2D/3D morphological parameters, as presented in Table 1. These parameters can be categorized into the following four groups: (a) Morphological parameters quantifying the total amount of UGI: total area, total volume, and total leaf area. (b) Morphological parameters reflecting the complexity of the UGI shape: total edge, landscape shape index, area-weighted mean shape index, volume-weighted mean shape index and leaf area-weighted mean shape index. (c) Morphological parameters describing the quantity in each UGI patch, reflecting the degree of fragmentation: mean patch size, mean patch volume, and mean patch leaf area. (d) Morphological parameters describing the 3D attributes of UGI in the entire statistical area: mean height, mean crown height and mean leaf area index.

Fig. 7(d) - (f) illustrates the distribution of 3 morphological parameters, namely, the total volume, volume-weighted mean shape index, and mean patch leaf area in the entire case study

area. A general morphological pattern of UGI can be recognized by examining the distribution of these parameters. The amount of UGI is low in the southwest and high in the northeast. The shape of UGI is generally more complex in the north and southeast portions. The continuity of 
UGI around the perimeter of the urban district is high. However, in the central portion dominated by residential buildings, the UGI is highly fragmented.
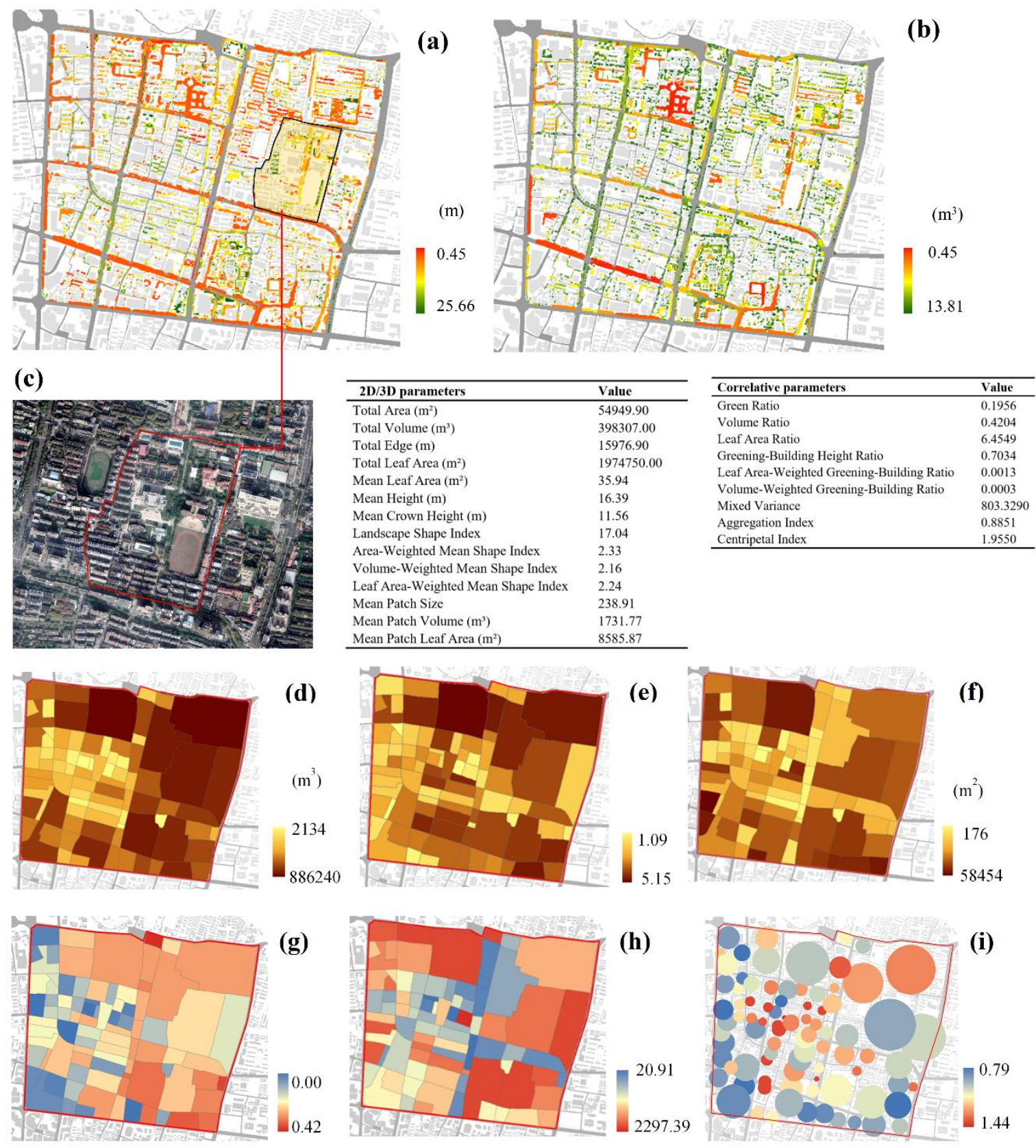

Fig. 7. The morphological attributes and parameters of UGI in the case study area: (a) crown

height, (b) canopy volume index, (c) the morphological parameters of the UGI in selected block, (d) total volume, (e) volume-weighted mean shape index, (f) mean patch leaf area, (g) volume- 
weighted greening-building ratio, (h) leaf area-weighted mixed variance, and (i) leaf areaweighted aggregation index.

\subsubsection{Correlative parameters}

The database contains the correlative parameters of UGI that quantify the relationship between UGI and its adjacent urban spaces in section 2.4.2. Fig. 7(g) - (i) shows the distribution of the 3 correlative parameters, namely, greening-building ratio (volume-weighted), mixed variance (leaf area-weighted), and aggregation index (leaf area-weighted), in the entire case study area. A low intensity UGI appears in the central residential area. In the commercial area of the southwest, the volume ratio of UGI to buildings is low, and UGI is distributed at the edge of the block. Fig. 7(h) illustrates the characteristic of the nonuniform mixing of UGI in the northwest and east blocks. In Fig. 7(i), the center of the circle is the geometric center point of UGI in each block, and the radius of the circle is the standard distance of UGI in formula (3).

As shown in Fig. 8, UGI presents different characteristics when different correlative morphological parameters are combined. In the high $M V$-high $A I$ block, UGI shows the obvious characteristic of gathering to a certain point. In the high $M V$-high $C I$ and high $A I$-high $C I$ blocks, UGI tends to gather at the geometric center of the blocks. In the low $A I$-high $M V$ and low $A I$ high $M V$ blocks, UGI gathers around the block edge and is uniformly distributed in every direction. In the high $A I$-low $C I$ and high $M V$-low $C I$ blocks, UGI gathers to one side of the edge. UGI in the low CI-low AI block shows the trend of being uniformly distributed on one side of the block. The UGI distribution in low MV blocks has no evident changes, no matter how the other parameters change. 


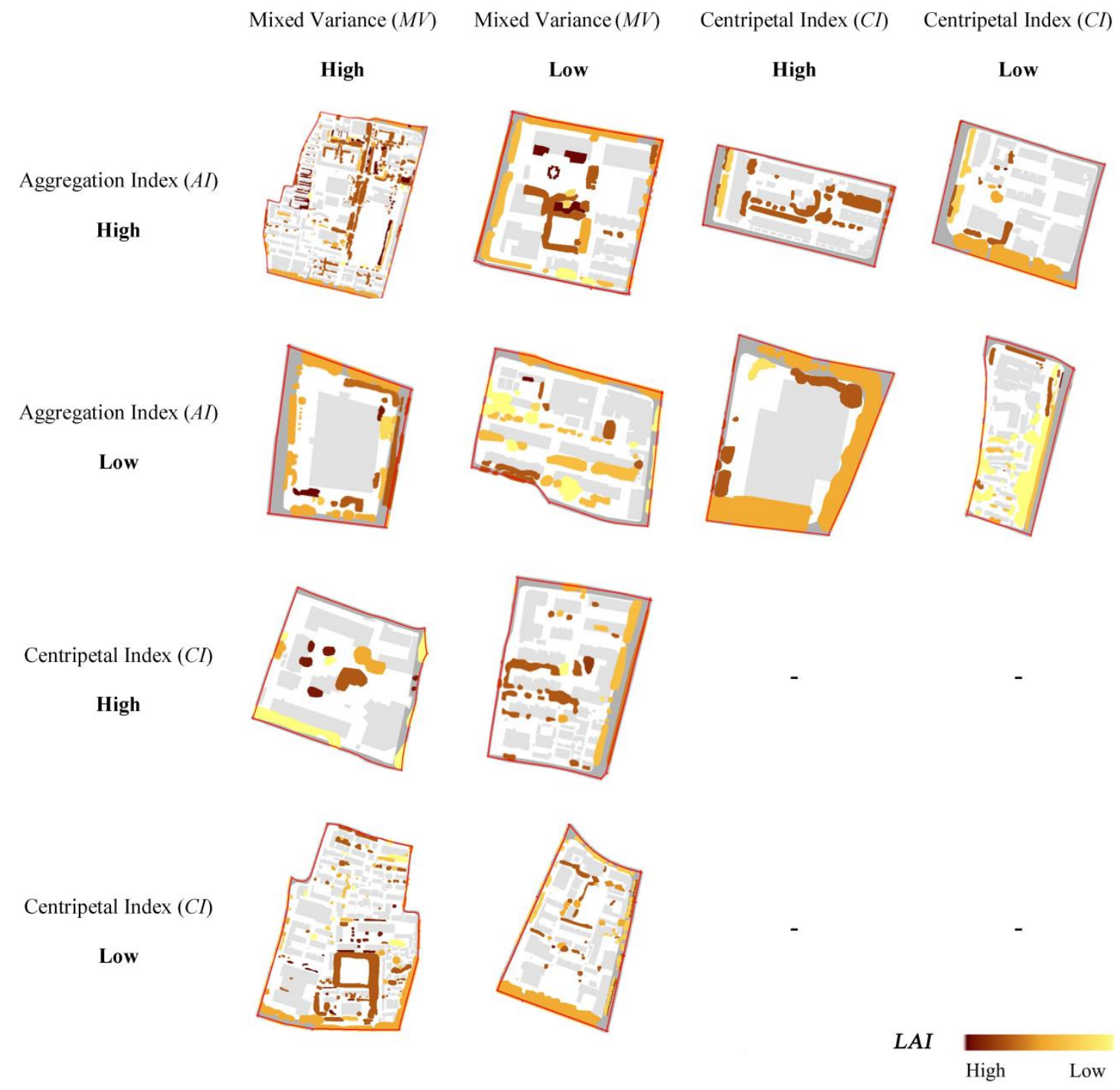

Fig. 8. Spatial distribution of the $L A I$ in typical blocks in the study area.

\subsubsection{Seasonal change of UGI}

The seasonal change of UGI is indicated by the temporally dynamic morphological parameters. Fig. 9 shows the monthly change of the total leaf area and Leaf area-weighted mean shape index in a selected block. These two morphological parameters are both temporally 
dynamic and dependent on the leaf area of the trees. More deciduous trees in the block would cause more significant changes to them.

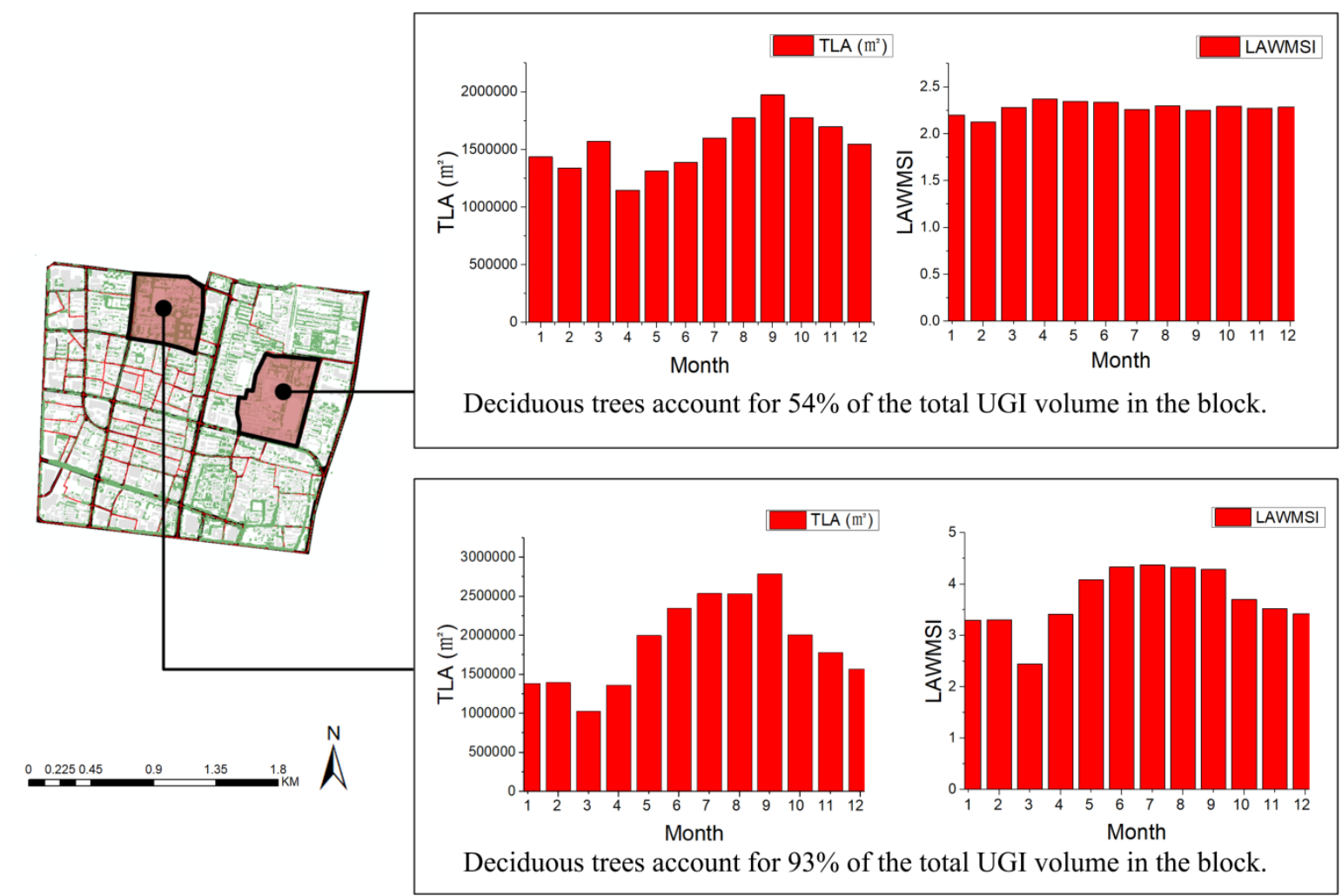

Fig. 9. Monthly changes of the total leaf area and leaf area-weighted mean shape index in blocks with different proportions of deciduous trees.

\section{Discussion}

\subsection{Applications of the 3D spatiotemporal database of UGI}

In section 3, the basic functions of the database are presented, including the visualization of UGI, the property table query of UGI morphological units and blocks, the analysis of its spatial pattern, etc. In addition to these basic functions, the database can be integrated with simulation programs and analytical models so that it can be used in the design and research of various urban sustainable subjects: (a) UGI has an important impact on the urban physical environment such as 
the thermal environment and heat island effect. The database provides various morphological information of UGI, including its location, size, tree species, volume, leaf area, etc., which are the basic data for simulating and analyzing the urban physical environment. (b) The database contains plenty of UGI morphological attributes and parameters, reflecting the 2D/3D UGI form and its relative relationship with the city background. By controlling the morphological parameters and rules, a bridge between UGI form and decision-making support in sustainable urban design can be conducted. These approaches include optimum selection of planning, adding important UGI form control index into the urban management system, and feedback on the optimized UGI form. (c) The database provides the 3D modeling and visualization method of UGI, which can be used to analyze the morphological parameters related to human activities, such as accessibility and visibility. These parameters are pivotal in evaluating the social and psychological benefits of UGI. In addition, the construction of the UGI data visualization platform provides an opportunity for the public to participate in UGI evaluation.

\subsection{Applicability of the methodology to different scales of urban districts and cities}

The case study presented in this paper is a $4 \mathrm{~km} 2$ urban district. The database takes into account the internal structure of single plant or multiple plants, containing the morphological factors such as leaf area, three-dimensional shape and temporal changes in UGI. These factors play an important role on its surrounding environment. Therefore, it is applicable for micro scale researches of UGI of different species and sizes. Compared with the previous data acquisition methods, the multitemporal satellite remote sensing images and street views used for the research are obtained from Google Earth and Baidu map, which are open source and easily accessible. Adjacent trees with similar attributes are merged into a basic morphological unit. This approach 
greatly improves the efficiency of data acquisition and is suitable for rapid modeling of UGI in large-scale urban areas. Although the methodology is valid for analysis of urban green structure in larger urban districts and even entire cities, the time and resources needed to develop such a database would inevitably increase. Therefore, a discussion is warranted regarding the applicability of the methodology to large-scale urban districts and cities.

When applying the methodology to a larger scale area, the increased workload includes the description of UGI morphological unit, the measurement and recording of the crown diameter, and the identification of tree species. Due to the complexity of the urban environment, such as the influence of building shadows and the high mixing state of tree species, the projection profile and tree species are difficult to identify by remote sensing and street views, and thus, they need to be supplemented by field investigations. In addition, analyzing the basic morphological attribute data and calculating the morphological parameters on GIS are also included. It takes one person 5 days to collect and arrange UGI data for a square kilometer.

The "crown diameter - crown height" equations were selected and based on previous studies, and have been confirmed through repetition at different growth stages and under different environments (Liang et al., 2017) .However, when the database is popularized in different regions with different climatic conditions and dominant species, it is necessary to use the measured data of the dominant tree species to establish a new local plane-height regression model and $L A D$ dynamic data, resulting in further increases in manpower and time. Field investigations and measurements of the samples of the dominant species in a study area are needed to collect the height and crown diameter of each species. To build the dynamic database of the dominant tree species, the $L A D$ of each dominant tree species should be measured once a month. 


\subsection{Time-dependency of the database}

Since the form of UGI changes dynamically with time, the database is time dependent. The time dependency is classified into three categories: (a) the annual change of the indicators represented by the leaf area, with distinctive dynamics characteristics that are cyclical in terms of the year; (b) steady increases caused by UGI growth, which is affected by the tree species, maintenance conditions and other factors; and (c) dynamic changes caused by artificial planting, logging, urban construction changes and other factors, the main features of which are random and unpredictable. By establishing the $L A D$ database using an annual cycle, the annual indicators can be reused every year without updating. However, the morphological changes caused by other factors will accumulate as time passes. Therefore, it is necessary to update the database in a timely manner to better serve the sustainable city because of the fast development and exploitation of cites.

\subsection{The weighting of the different contributions of the UGI elements}

In the 2D analysis method, patches with lager area have higher contribution to the ecological function. However, studies have shown that tall trees play a greater role in cooling, providing shadow, carbon storage, wind and rainwater regulation, human perception and biodiversity than grassland and shrub (Prather, Eppley, \& Rosenstiel,2018; Manickathan et al., 2018; Sodoudi, Zhang, Chi, Müller, \& Li,2018; Gerstenberg \& Hofmann,2016). The database provides three kinds of weight parameters: area, crown volume and leaf area. From a 3D perspective, the UGI units with high canopy volume make greater contribution in terms of perception and environmental regulating. Furthermore, in the condition of same volume, the UGI units with high 
leaf area make greater contribution to the physical environment. The weight parameters should be selected according to the requirements of the actual research.

\section{Conclusion and outlooks}

As an indispensable component of cities, UGI contributes in many ways to urban sustainability. Its morphology plays an important role in determining the UGI's functions and effectiveness. A systematic approach to develop a 3D spatiotemporal morphological database for UGI is proposed. The database is built on a complete set of information describing the form of UGI on both a plane and in the vertical direction, thus making it three dimensional. The temporal change of UGI is considered by identifying deciduous trees and their time-dependent morphological features. In addition, three categories of morphological parameters of UGI are calculated and integrated in the database. Among these three categories, the correlative parameters reflect and quantify the morphological correlation between UGI and its adjacent and surrounding urban space. The proposal and inclusion of correlative parameters enables us to study the UGI morphology and its impact on urban sustainability in the context of cities, thus avoiding the limitations of treating UGI in an isolated way.

The database, developed in ArcGIS, offers basic functions such as visualization, data query and retrieval, morphological calculation, view analysis, and data output. The application of the database can be further expanded if it is integrated with other models or programs for urban sustainability analysis. Examples include urban physical environment analysis, decision-making support in sustainable urban design, and evaluation of the social and psychological effect of UGI. In the future, to improve the 3D spatiotemporal morphological database of UGI in terms of the efficiency of the approach and its applications, several research topics are worthwhile. First and foremost, more efficient data acquisition techniques to collect the basic morphological 
information of UGI should be developed. The aim is to significantly reduce the time and labor cost for data acquisition so that the methodology can be applied to large-scale urban districts and cities. Second, simulation models and programs for urban sustainability issues such as the urban heat island effect and pollutant dispersion can be linked with the database. The morphological information and parameters in the database are prerequisites for the simulation. Last but not least, the means of integrating the database into the workflow of sustainable urban planning and design should be explored. This approach can provide urban planners and designers with an effective tool to better consider and incorporate UGI in their projects.

\section{References}

Abd Aziz, H., \& Rasidi, M. H. (2013). Study of Habitat Indicator: Openness and complexity level in the parks of Putrajaya. Procedia-Social and Behavioral Sciences, 85, 332-344. https://doi.org/10.1016/j.sbspro.2013.08.363

Ahern, J. (1995). Greenways as a planning strategy. Landscape and Urban Planning, 33(1), 131155. https://doi.org/10.1016/0169-2046(95)02039-V

Aydin, M. B. S., \& Çukur, D. (2012). Maintaining the carbon-oxygen balance in residential areas: A method proposal for land use planning. Urban forestry \& urban greening, 11(1), 87-94. https://doi.org/10.1016/j.ufug.2011.09.008

Ballinas, M., \& Barradas, V. L. (2016). The Urban Tree as a Tool to Mitigate the Urban Heat Island in Mexico City: A Simple Phenomenological Model. Journal of Environmental Quality, 45(1), 157-166. https://doi.org/10.2134/jeq2015.01.0056

Baycan-Levent, T., Vreeker, R., \& Nijkamp, P. (2009). A multi-criteria evaluation of green spaces in European cities. European Urban and Regional Studies, 16(2), 193-213. https://doi.org/10.1177/0969776408101683 
Belmeziti, A., Cherqui, F., \& Kaufmann, B. (2018). Improving the multi-functionality of urban green spaces: Relations between components of green spaces and urban services. Sustainable cities and society, 43, 1-10. https://doi.org/10.1016/j.scs.2018.07.014

Berland, A., Shiflett, S. A., Shuster, W. D., Garmestani, A. S., Goddard, H. C., Herrmann, D. L.,\& Hopton, M. E. (2017). The role of trees in urban stormwater management. Landscape and Urban Planning, 162, 167-177. https://doi.org/10.1016/j.landurbplan.2017.02.017

Bilgili, B. C., \& Gökyer, E. (2012). Urban green space system planning. Landscape planning, 107

Bryant, M. M. (2006). Urban landscape conservation and the role of ecological greenways at local and metropolitan scales. Landscape and urban planning, 76(1-4), 23-44. https://doi.org/10.1016/j.landurbplan.2004.09.029

Burton, E., Jenks, M., \& Williams, K. (2003). The compact city: a sustainable urban form?. Routledge.

Byrne, J., \& Sipe, N. (2010). Green and open space planning for urban consolidation - A review of the literature and best practice.

Chen, X., Zhao, P., Hu, Y., Ouyang, L., Zhu, L.,... Ni, G. (2019). Canopy transpiration and its cooling effect of three urban tree species in a subtropical city- Guangzhou, China. Urban Forestry \& Urban Greening, 43, 126368. https://doi.org/10.1016/j.ufug.2019.126368 Cheng, H., Zhang, K., Liu, C., Zou, X., Kang, L., Chen, T.,... Fang, Y. (2018). Wind tunnel study of airflow recovery on the lee side of single plants. Agricultural and Forest Meteorology, 263, 362-372. https://doi.org/10.1016/j.agrformet.2018.08.025 
Clark, K. H., \& Nicholas, K. A. (2013). Introducing urban food forestry: a multifunctional approach to increase food security and provide ecosystem services. Landscape Ecology, 28(9), 1649-1669. https://doi.org/10.1007/s10980-013-9903-z

Cummins, S. K., \& Jackson, R. J. (2001). The built environment and children's health. Pediatric Clinics of North America, 48(5), 1241-1252. https://doi.org/10.1016/S0031-3955(05)70372-2

Dunnett, N., Swanwick, C., \& Woolley, H. (2002). Improving urban parks, play areas and green spaces. London: Department for transport, local government and the regions.

Forman, R.T.T. \& Godron, M. (1986). Landscape Ecology. Wiley, New York.

Forman, R.T.T. (1995). Land Mosaics: The Ecology of Landscapes and Regions. Cambridge University Press, Cambridge.

Gao, X., \& Asami, Y. (2007). Effect of urban landscapes on land prices in two Japanese cities. Landscape and urban planning, 81(1-2), 155-166.

https://doi.org/10.1016/j.landurbplan.2006.11.007

Gerstenberg, T., \& Hofmann, M. (2016). Perception and preference of trees: A psychological contribution to tree species selection in urban areas. Urban Forestry \& Urban Greening, 15, 103-111. https://doi.org/10.1016/j.ufug.2015.12.004

Godefroid, S. (2001). Temporal analysis of the Brussels flora as indicator for changing environmental quality. Landscape and urban planning, 52(4), 203-224. https://doi.org/10.1016/S0169-2046(00)00117-1

Guo, X. (2009). Research on the living vegetation volume of common landscape plants in Nanjing. Master's thesis, Nanjing Forestry University, Nanjing. (In Chinese) http://cdmd.cnki.com.cn/Article/CDMD-10298-2009201152.htm. 
Gustafson, E. J. (1998). Quantifying landscape spatial pattern: what is the state of the art?

Ecosystems, 1(2), 143-156. https://doi.org/10.1007/s100219900011

Haaland, C., \& van den Bosch, C. K. (2015). Challenges and strategies for urban green-space planning in cities undergoing densification: A review. Urban Forestry \& Urban Greening, 14(4), 760-771. https://doi.org/10.1016/j.ufug.2015.07.009

Hansmann, R., Hug, S., \& Seeland, K. (2007). Restoration and stress relief through physical activities in forests and parks. Urban Forestry \& Urban Greening, 6(4), 213-225.

https://doi.org/10.1016/j.ufug.2007.08.004

Hasenauer, H., \& Monserud, R. A. (1996). A crown ratio model for Austrian forests. Forest Ecology and Management, 84(1), 49-60. https://doi.org/10.1016/0378-1127(96)03768-1

Heisler, G. M. (1990). Mean wind speed below building height in residential neighborhoods with different tree densities. ASHRAE Transactions. 96 (1): 1389-1396.

Hsieh, C., Li, J., Zhang, L., \& Schwegler, B. (2018). Effects of tree shading and transpiration on building cooling energy use. Energy and Buildings, 159, 382-397.

https://doi.org/10.1016/j.enbuild.2017.10.045

Jongman, R. H. G., Külvik, M., \& Kristiansen, I. (2004). European ecological networks and greenways. Landscape and Urban Planning, 68(2), 305-319. https://doi.org/10.1016/S0169$\underline{2046(03) 00163-4}$

Kowarik, I. (2019). The “Green Belt Berlin” : Establishing a greenway where the Berlin Wall once stood by integrating ecological, social and cultural approaches. Landscape and Urban Planning, 184, 12-22. https://doi.org/10.1016/j.landurbplan.2018.12.008 
La Rosa, D. (2014). Accessibility to greenspaces: GIS based indicators for sustainable planning in a dense urban context. Ecological Indicators, 42, 122-134.

https://doi.org/10.1016/j.ecolind.2013.11.011

Liang, H., Li, W., Zhang, Q., Zhu, W., Chen, D., Liu, J.,... Shu, T. (2017). Using unmanned aerial vehicle data to assess the three-dimension green quantity of urban green space: A case study in Shanghai, China. Landscape and Urban Planning, 164, 81-90.

https://doi.org/10.1016/j.landurbplan.2017.04.006

Little, C. E. (1995). Greenways for America: JHU Press.

Li, X., Xiao, Q., Niu, J., Dymond, S., van Doorn, N. S., Yu, X.,... Li, J. (2016). Process-based rainfall interception by small trees in Northern China: The effect of rainfall traits and crown structure characteristics. Agricultural and Forest Meteorology, 218-219, 65-73. https://doi.org/10.1016/j.agrformet.2015.11.017

Lo, A. Y., \& Jim, C. Y. (2012). Citizen attitude and expectation towards greenspace provision in compact urban milieu. Land use policy, 29(3), 577-586.

https://doi.org/10.1016/j.landusepol.2011.09.011

Lu, J. (2015). Landscape ecology, urban morphology, and CBDs: an analysis of the Columbus, Ohio Metropolitan Area. Applied Geography, 60, 301-307.

https://doi.org/10.1016/j.apgeog.2014.11.004

Madureira, H., Andresen, T., \& Monteiro, A. (2011). Green structure and planning evolution in Porto. Urban Forestry \& Urban Greening, 10(2), 141-149.

https://doi.org/10.1016/j.ufug.2010.12.004 
Majumdar, S., Deng, J., Zhang, Y., \& Pierskalla, C. (2011). Using contingent valuation to estimate the willingness of tourists to pay for urban forests: A study in Savannah, Georgia. Urban Forestry \& Urban Greening, 10(4), 275-280. https://doi.org/10.1016/j.ufug.2011.07.006 Manickathan, L., Defraeye, T., Allegrini, J., Derome, D., \& Carmeliet, J. (2018). Comparative study of flow field and drag coefficient of model and small natural trees in a wind tunnel. Urban Forestry \& Urban Greening, 35, 230-239. https://doi.org/10.1016/j.ufug.2018.09.011 Maruani, T., \& Amit-Cohen, I. (2007). Open space planning models: A review of approaches and methods. Landscape and Urban Planning, 81(1), 1-13.

https://doi.org/10.1016/j.landurbplan.2007.01.003

McMichael, A. J. (2000). The urban environment and health in a world of increasing globalization: issues for developing countries. Bulletin of the world Health Organization, 78, $1117-1126$

McPherson, E. G. (1994). Chicago's urban forest ecosystem: results of the Chicago Urban Forest Climate Project (Vol. 186). US Department of Agriculture, Forest Service, Northeastern Forest Experiment Station.

Noh, Y. (2019). Does converting abandoned railways to greenways impact neighboring housing prices? Landscape and urban planning, 183, 157-166.

https://doi.org/10.1016/j.landurbplan.2018.11.002

Nowak, D. J., Crane, D. E., \& Stevens, J. C. (2006). Air pollution removal by urban trees and shrubs in the United States. Urban forestry \& urban greening, 4(3-4), 115-123. https://doi.org/10.1016/j.ufug.2006.01.007 
O'Neill, R. V., Krummel, J. R., Gardner, R. E. A., Sugihara, G., Jackson, B., DeAngelis, D. L.,... Christensen, S. W. (1988). Indices of landscape pattern. Landscape ecology, 1(3), 153-162. https://doi.org/10.1007/BF00162741

Pathak, V., Tripathi, B. D., \& Mishra, V. K. (2011). Evaluation of anticipated performance index of some tree species for green belt development to mitigate traffic generated noise. Urban forestry \& urban greening, 10(1), 61-66. https://doi.org/10.1016/j.ufug.2010.06.008

Perini, K., \& Magliocco, A. (2014). Effects of vegetation, urban density, building height, and atmospheric conditions on local temperatures and thermal comfort. Urban Forestry \& Urban Greening, 13(3), 495-506. https://doi.org/10.1016/j.ufug.2014.03.003

Pickett, S. T., \& Cadenasso, M. L. (2008). Linking ecological and built components of urban mosaics: an open cycle of ecological design. Journal of Ecology, 8-12. https://doi.org/10.1111/j.1365-2745.2007.01310.x

Rahman, M. A., Stratopoulos, L. M. F., Moser-Reischl, A., Zölch, T., Häberle, K., Rötzer, T.,... Pauleit, S. (2020). Traits of trees for cooling urban heat islands: A meta-analysis. Building and Environment, 170, 106606. https://doi.org/10.1016/j.buildenv.2019.106606

Prather, H. M., Eppley, S. M., \& Rosenstiel, T. N. (2018). Urban forested parks and tall tree canopies contribute to macrolichen epiphyte biodiversity in urban landscapes. Urban Forestry \& Urban Greening, 32, 133-142. https://doi.org/10.1016/j.ufug.2018.04.012

Roy, S., Byrne, J., \& Pickering, C. (2012). A systematic quantitative review of urban tree benefits, costs, and assessment methods across cities in different climatic zones. Urban Forestry \& Urban Greening, 11(4), 351-363. https://doi.org/10.1016/j.ufug.2012.06.006 
Rudd, H., Vala, J., \& Schaefer, V. (2002). Importance of backyard habitat in a comprehensive biodiversity conservation strategy: a connectivity analysis of urban green spaces. Restoration ecology, 10(2), 368-375. https://doi.org/10.1046/j.1526-100X.2002.02041.X

Russell, E. S., Liu, H., Thistle, H., Strom, B., Greer, M.,... Lamb, B. (2018). Effects of thinning a forest stand on sub-canopy turbulence. Agricultural and Forest Meteorology, 248, 295-305. doi - 10.1016/j.agrformet.2017.10.019

Schirmer, P. M., \& Axhausen, K. W. (2016). A multiscale classification of urban morphology. Journal of Transport and Land Use, 9(1), 101-130. https://doi.org/10.5198/jtlu.2015.667

Sodoudi, S., Zhang, H., Chi, X., Müller, F., \& Li, H. (2018). The influence of spatial configuration of green areas on microclimate and thermal comfort. Urban Forestry \& Urban Greening, 34, 85-96. https://doi.org/10.1016/j.ufug.2018.06.002

Tallis, M., Taylor, G., Sinnett, D., \& Freer-Smith, P. (2011). Estimating the removal of atmospheric particulate pollution by the urban tree canopy of London, under current and future environments. Landscape and Urban Planning, 103(2), 129-138.

https://doi.org/10.1016/j.landurbplan.2011.07.003

Tan, K. W. (2006). A greenway network for singapore. Landscape and Urban Planning, 76(1), 45-66. https://doi.org/10.1016/j.landurbplan.2004.09.040

Tan, K. W. (2006). A greenway network for Singapore. Landscape and Urban Planning, 76(14), 45-66. https://doi.org/doi - 10.1016/j.landurbplan.2004.09.040

Taylor, L., \& Hochuli, D. F. (2017). Defining greenspace: Multiple uses across multiple disciplines. Landscape and Urban Planning, 158, 25-38.

https://doi.org/10.1016/j.landurbplan.2016.09.024 
Tong, Z., Baldauf, R. W., Isakov, V., Deshmukh, P., \& Max Zhang, K. (2016). Roadside vegetation barrier designs to mitigate near-road air pollution impacts. Science of the Total Environment, 541, 920-927. https://doi.org/10.1016/j.scitotenv.2015.09.067

Turner, M. G. (2005). Landscape ecology: what is the state of the science?. Annu. Rev. Ecol. Evol. Syst., 36, 319-344. https://doi.org/10.1146/annurev.ecolsys.36.102003.152614 United Nations. (2018). World urbanization prospects 2018.

Uy, P. D., \& Nakagoshi, N. (2007). Analyzing urban green space pattern and eco-network in Hanoi, Vietnam. Landscape and Ecological Engineering, 3(2), 143-157. https://doi.org/10.1007/s11355-007-0030-3

Walmsley, A. (1995). Greenways and the making of urban form. Landscape and urban planning, 33(1-3), 81-127. https://doi.org/10.1016/0169-2046(95)02015-L

Wang, C., Li, Q., \& Wang, Z. (2018). Quantifying the impact of urban trees on passive pollutant dispersion using a coupled large-eddy simulation-Lagrangian stochastic model. Building and Environment, 145, 33-49. https://doi.org/10.1016/j.buildenv.2018.09.014

Wang, J., Zhou, W., Jiao, M., Zheng, Z., Ren, T.,... Zhang, Q. (2020). Significant effects of ecological context on urban trees' cooling efficiency. ISPRS Journal of Photogrammetry and Remote Sensing, 159, 78-89. https://doi.org/10.1016/j.isprsjprs.2019.11.001

Whitford, V., Ennos, A. R., \& Handley, J. F. (2001). “City form and natural process”indicators for the ecological performance of urban areas and their application to Merseyside, UK. Landscape and urban planning, 57(2), 91-103. https://doi.org/10.1016/S0169-2046(01)00192-X Wilby, R. L., \& Perry, G. L. (2006). Climate change, biodiversity and the urban environment: a critical review based on London, UK. Progress in physical geography, 30(1), 73-98. https://doi.org/10.1191/0309133306pp470ra 
Wolch, J. R., Byrne, J., \& Newell, J. P. (2014). Urban green space, public health, and environmental justice: The challenge of making cities 'just green enough'. Landscape and urban planning, 125, 2. https://doi.org/10.1016/j.landurbplan.2014.01.017

Xin, Q., Dai, Y., Li, X., Liu, X., Gong, P., \& Richardson, A. D. (2018). A steady-state approximation approach to simulate seasonal leaf dynamics of deciduous broadleaf forests via climate variables. Agricultural and Forest Meteorology, 249, 44-56.

https://doi.org/10.1016/j.agrformet.2017.11.025 34-244

Zhou, J., \& Sun, T. (1995). Study on remote sensing model of three dimensional green biomass and the estimation of environmental benefits of greenery. Remote Sensing of Environment China, 10(3), 162-174. (In Chinese) http://en.cnki.com.cn/Article_en/CJFDTotal-YGXB503.001.htm Zhou, X., \& Parves, R. M. (2012). Social benefits of urban green space: A conceptual framework of valuation and accessibility measurements. Management of Environmental Quality: An International Journal, 23(2), 173-189. https://doi.org/10.1016/j.agrformet.2017.11.025 